Original Research Article

\title{
An assessment of knowledge, attitude and practices (KAP) towards warfarin medication among patients with prosthetic valve in a tertiary care hospital of South India
}

\author{
Gopisankar M. G.*, Surendiran A., Hemachandren M.
}

Department of Pharmacology, JIPMER, Puducherry, India

Received: 09 August 2018

Revised: 20 August 2018

Accepted: 24 August 2018

*Correspondence to:

Dr. Gopisankar M. G.,

Email: spaarkingo@gmail.com

Copyright: () the author(s), publisher and licensee Medip Academy. This is an openaccess article distributed under the terms of the Creative Commons Attribution NonCommercial License, which permits unrestricted noncommercial use, distribution, and reproduction in any medium, provided the original work is properly cited.

\begin{abstract}
Background: Warfarin is a drug with narrow therapeutic index. It requires varied adequate doses for achieving target INR so as to prevent episodes of thromboembolism. It is important to properly educate the patient while prescribing this drug to reduce the side effects and maintain perfect anticoagulation status. This study was done to assess the baseline Knowledge, Attitude and Practices (KAP) towards warfarin medication among patients with cardiac valve replacement in a tertiary care hospital of south India to get a baseline data which can recommend implementation of health education programs targeting these patients.

Methods: The study included patients on treatment with warfarin maintenance therapy for a period of not less than three months following cardiac valve replacement in the months of October 2016 to October 2017. The questionnaire included 39 questions of qualitative and quantitative basis, which was scored for a total of 50 and analysed using SPSS software.

Results: About 240 patients were interviewed who attended cardiothoracic vascular surgery outpatient department and taking warfarin for at least 3 months following surgery of valve replacement. Patients were divided into two groups. Group A included patients who achieved target INR and group B are those out of target INR. 15.7 percent (35) had low score, 76.2 (160) had medium score and 15 (7.1) percent had high scores in group A. In group B 22(81.5\%) had medium score and $5(18.5 \%)$ had high score. The median score was more among patients with higher education $(\mathrm{p}=0.01)$. There was no significant difference between scores between different age groups or profession.

Conclusions: Lack of adequate knowledge exists in patients who are followed in CTVS OPD when assessed about the basic nature of their disease and drug use. It has been shown that group B had more score which may be due to more education they may have received owing to non-attainment of target INR. This study acts as a baseline and thus advocates the need of proper patient education for patients taking warfarin which may improve the treatment outcome.
\end{abstract}

Keywords: Patient cantered communication, Warfarin KAP

\section{INTRODUCTION}

Warfarin is a commonly used anticoagulant for prevention of thrombosis in patients with valvular heart diseases. It shows high inter-individual variation in dose requirement. The dose required to achieve target INR (2-3) in valvular heart disease varies around tenfold in between patients. ${ }^{1,2}$ The dose variation is due to different factors, both genetic and non-genetic. It is often difficult for the physicians to prescribe the ideal dose which achieves a stable INR without causing any side effects. One of the most important ways to get a good disease control is patient 
education. But this aspect is usually not addressed in our setup. Most physicians will try to address issues of poor disease control by adding or changing the drugs or its dose and dosage, e.g. changing of warfarin to acenocoumarol is commonly done in clinics as the later one gives bettercontrolled INR but with higher costs. They try to do more costly investigations to find alternate reasons for poor control of the condition. Though this is necessary in many cases, we often forget that it can be due to lack of knowledge in the patient which leads to an improper way of taking drugs and thus making it ineffective. Valvular heart disease management is mostly life-long. Studies have shown that proper patient participation can improve the care in chronic diseases and reduce medication errors. ${ }^{3}$ The first step toward achieving good patient participation is proper patient education. Educating patients is an important part in tackling warfarin resistance. The mode of education that you want to give depends upon the current status of knowledge, attitude and practice among patients. This study assessed these domains in patients under follow up in cardiothoracic vascular surgery OPD following valve replacement surgery in a tertiary care hospital in south India. This study can be considered as a baseline study which can give insights into the need of future implementation awareness programmes for such patients with chronic diseases.

\section{METHODS}

About 240 patients who had underwent valve replacement and taking warfarin were recruited in the study period of one year (October 2016 to October 2017). The knowledge, attitude and practice about the drug and also the surgery was assessed using a questionnaire initially made in English and later translated to Tamil.

\section{Questionnaire design and data analysis}

The knowledge, attitude and practice of patients were assessed using a questionnaire which included questions developed from discussions with physicians and referring standard textbooks of pharmacology. Many relevant domains were taken from a pre tested questionnaires available, e.g., AKA questionnaire and modified to match our clinical and social setup., ${ }^{4,5}$

The questionnaire involved both qualitative and quantitative aspects of the disease which determines the outcome. Informed written consent was obtained from all the patients who are willing to participate in the study. The questionnaire assessed many important aspects of KAP in the patient population. They were patient's attitude towards his disease, surgery done and drug effect, knowledge about warfarin and its effects and monitoring of the therapy. It also considered the actual practice of the patient in taking the drug, when he would return to OPD and handling of complications by the patient. The questions were divided into three modules for knowledge, attitude and practice with 18, 7 and 14 questions respectively. We used a scalar method of scoring for the assessment. In knowledge out of 18 questions, expect for three questions all others scored 1 for right answer and 0 for the incorrect response. One question about number of doses skipped in last three months were categorised into four options and given 0 to 3 marks values. Other question about the reason for surgery was given three values of 0 to 2 and one which assess the expected complication was valued the same. The knowledge module was evaluated as poor knowledge and fair knowledge in most of the questions. The final total score of KAP questionnaire was divided into low, medium and high scores. The score was distributed into three modules. Knowledge part included 19 questions of 20 marks. Attitude module had 7 questions of 8 marks and practice module had 14 questions of 22 marks. Total number of questions were 39 and the overall score obtained if all of the questions were answered correctly was 50 . Those who scored more than or equal to $70 \%$ (score $\geq 35$ ) were high score, those between 40 to $69.9 \%$ came under medium score $(20 \geq$ score $<35)$ and scores below $40 \%$ (score <20) were considered low level. The scoring system used was similar to other studies of KAP done in the past. ${ }^{4,5}$

\section{Statistical analysis}

All continuous variables in patient demography were expressed as mean and standard deviation. Scores were represented as median and range. Categorical variables were expressed in frequency and percentages. Comparison of KAP score was done using Mann Whitney $U$ test or Kruskal Wallis test and post hoc tests. The statistical significance was kept as $<0.05$.

\section{RESULTS}

\section{Demographic details of the patients}

The patients after recruitment was divided into two groups. One group (group A) of patients who achieved stable INR (2-3) with a dose of warfarin for 3 months.

The other group (group B) included patients who didn't achieve stable INR even with maximal clinical dose of warfarin, i.e. more than $52.5 \mathrm{mg}$ per week. We divided the group into two because we expect a more proper patient education level in those who are not achieving INR with routine doses of warfarin. The total number of participants were 240, out of which 210 achieved target INR with a particular dose of warfarin for three months. About 30 of the participants didn't reach target INR with the maximum dose of warfarin. Group A, 59\% (124) were females and $41 \%$ (86) were males. In group B $60 \%$ (16) females and $40 \%$ (11) males. Mean age of respondents in group A was $38 \pm 11$ with minimum age of 18 and maximum age of 82 . The mean age in group $b$ was $36 \pm 11$ with minimum age of 18 and maximum age of 61 . Most of the patients belonged to poor socioeconomic group as recorded in their case sheets. Table 1 shows the socioeconomic profile of the patients and categories of age in group A. All of them 
received warfarin as a part of anticoagulation following cardiac valve replacement.

Table 1: The socioeconomic profile of the patients and some demographic details of group A.

\begin{tabular}{|ll|}
\hline Participant details & Frequency (\%) \\
\hline Age if the respondent & \\
\hline Less than 20 & $11(5.2)$ \\
\hline $21-30$ & $42(20)$ \\
\hline $31-40$ & $67(31.9)$ \\
\hline $41-50$ & $61(29)$ \\
\hline More than 50 & $29(13.8)$ \\
\hline Education of the respondent & \\
\hline Illiterate & $21(10)$ \\
\hline Primary & $78(37.1)$ \\
\hline Middle & $97(46.2)$ \\
\hline Graduate & $14(6.7)$ \\
\hline Profession of the respondent & \\
\hline Unskilled labour & $46(21.9)$ \\
\hline House wife & $85(40.5)$ \\
\hline Skilled labour & $30(14.3)$ \\
\hline Government service & $10(4.8)$ \\
\hline Private service & $29(13.8)$ \\
\hline Unemployed & $10(4.8)$ \\
\hline
\end{tabular}

\section{Knowledge of warfarin therapy}

The median score in group A patients was $12(04,15)$ and in group B was $14(10,16)$ out of 20 scores. In group A $80.5 \%$ knew about their disease as a heart disease and rest specified that they had valvular heart disease. Around $20 \%$ knew that the surgery was valve repair or replacement.
More than $90 \%$ (195) of the respondents knew the reason for prescribing warfarin as to prevent blood clotting. About $78 \%$ of patients knew that bleeding is the side effect of warfarin and when they have to come to emergency room. Around $80 \%$ of them knew the dose which they are taking daily. Other questions regarding knowledge module of both the groups, where the score was less are given in Table 2 .

\section{Attitude towards warfarin therapy}

Attitude was assessed regarding the need of surgery, lifelong medications, control of disease. The questions also addressed easiness of attending OPD and it importance understood by the patients. About $81 \%$ of the patients believed that surgery was absolutely necessary for them to relieve their symptoms. Around $43 \%$ believed that they can stop taking the medications at some point of time. Around $92 \%$ believed that it is important to come to OPD whenever they are asked for. Around $83 \%$ were hopeful that their disease can be kept under control by surgery done and drugs taken. There was difficulty in coming got OPD every month for $70 \%$ of the patients due to several reasons. Patients never skipped any dose fearing of any adverse effects by the drug.

\section{Practices}

Various dimensions of practice of drug consumption in patients were assessed and are tabulated in Table 3. It included aspects related to proper taking of medications like time, food intake, skipping of dose, etc. It also included possible situations that the patients may face or would have faced.

Table 2: Proportion of patients divided as with fair knowledge and no knowledge according to the scores obtained in knowledge module.

\begin{tabular}{|lllll|}
\hline Knowledge module & $\begin{array}{l}\text { No knowledge } \\
\text { Group A }\end{array}$ & $\begin{array}{l}\text { Fair knowledge } \\
\text { Group A }\end{array}$ & $\begin{array}{l}\text { No knowledge } \\
\text { Group B }\end{array}$ & $\begin{array}{l}\text { Fair knowledge } \\
\text { Group B }\end{array}$ \\
\hline Effect of food on warfarin & 34 & 66 & 11 & 89 \\
\hline Effect of alcohol on INR & 96 & 4 & 92 & 8 \\
\hline Effect of other medications on warfarin & 69 & 31 & 56 & 44 \\
\hline $\begin{array}{l}\text { Time for the effect of warfarin to leave the } \\
\text { body }\end{array}$ & 96 & 4 & 100 & 0 \\
\hline Meaning of INR & 100 & 0 & 63 & 37 \\
\hline Need of coming to OPD & 40 & 60 & 19 & 81 \\
\hline
\end{tabular}

\section{DISCUSSION}

This study showed a significant gap in KAP level of the patients regarding the warfarin usage. When we considered the total score of KAP, 15.7 percent (35) had low score, 76.2 (160) had medium score and 15 (7.1) percent had high scores in group A. Every patient has the right to know about his disease condition, name of the medicine, reason for prescribing the medicine and how the medicine acts on him. This has become relevant as we shifted from paternalistic concept of doctor-patient relationship to mutualism. Communication which is patient centred has proven benefits. ${ }^{7,8}$ In this study, most of the patients had a basic awareness of the disease as a 
heart disease at least. Many knew about the procedure as valve replacement. Gap exists in knowledge about effects of food on warfarin.

Table 3: Proportion of patients following good practice.

\begin{tabular}{|lll|}
\hline Practice & \multicolumn{2}{l|}{ Good practice (\%) } \\
\hline Proper time of drug intake & 90 & 88 \\
\hline $\begin{array}{l}\text { Never skipped a dose in last } \\
\text { three months }\end{array}$ & 87 & 93 \\
\hline Proper food-drug timing & 10 & 26 \\
\hline Frequency of PT-INR testing & 69 & 93 \\
\hline Proper OPD attendance & 88 & 100 \\
\hline Proper physical activity & 5 & 4 \\
\hline $\begin{array}{l}\text { Good idea about brand of } \\
\text { drugs and effects }\end{array}$ & 7 & 19 \\
\hline $\begin{array}{l}\text { Correct intake of vegetables } \\
\text { Practice regarding } \\
\text { multivitamin intake }\end{array}$ & 31 & 70 \\
\hline $\begin{array}{l}\text { Proper dealing of running out } \\
\text { of drugs situation }\end{array}$ & 7 & 70 \\
\hline $\begin{array}{l}\text { Informing dental doctor about } \\
\text { warfarin intake }\end{array}$ & 8 & 19 \\
\hline Usage of Alternative medicine & 26 & 44 \\
\hline Situation of forgotten dose & 70 & 48 \\
\hline
\end{tabular}

One third of the patients still didn't have a clear idea regarding the intake of green leafy vegetables. Authors know that leafy vegetables contain vitamin $\mathrm{K}$ and which can lead to reduce effect of warfarin. So, people when advised can lead to complete avoidance of leafy vegetables. This we could find as a significant problem because while analysing their case sheets we found that $6 \%$ of the patients had to take B complex capsules for some reason which may be due to strict avoidance of leafy vegetables. It is better to advise them to have equal amount of leafy vegetables every day which won't affect the required dose of warfarin. Around $98 \%$ of the participants were non-alcoholic but they didn't have proper idea regarding the change in INR due to alcoholism.

The knowledge about the effect of warfarin to leave their body was poor among patients, a point which has got practical importance. In some cases, patient can judge its efficacy of drug as by reliving of symptoms. In this case, the patients can be educated in such a way that INR value can be used by the patient to monitor his health. In our study we found that most of them didn't have the idea of meaning for INR. Idea that INR shows the activity of warfarin will help the patients to plan re visits when its value goes above 3 . This is more important if they are not under proper follow up in the same hospital. Attitude towards illness and drug was found to be good. Most of them believed in the treatment and its outcomes. But many believed that they could stop the medications at some point which is actually may not be possible.

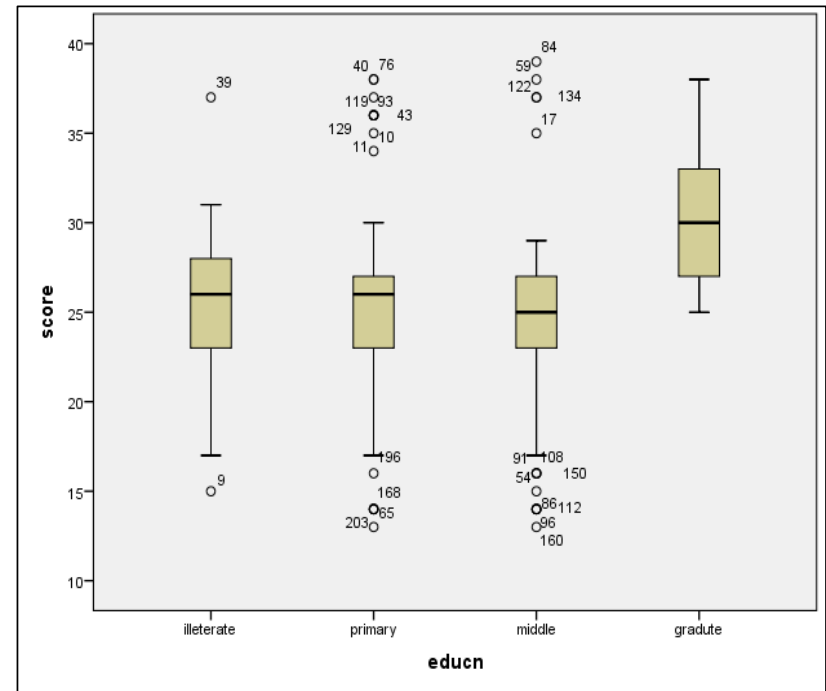

Figure 1: Score of knowledge module in different categories of literacy.

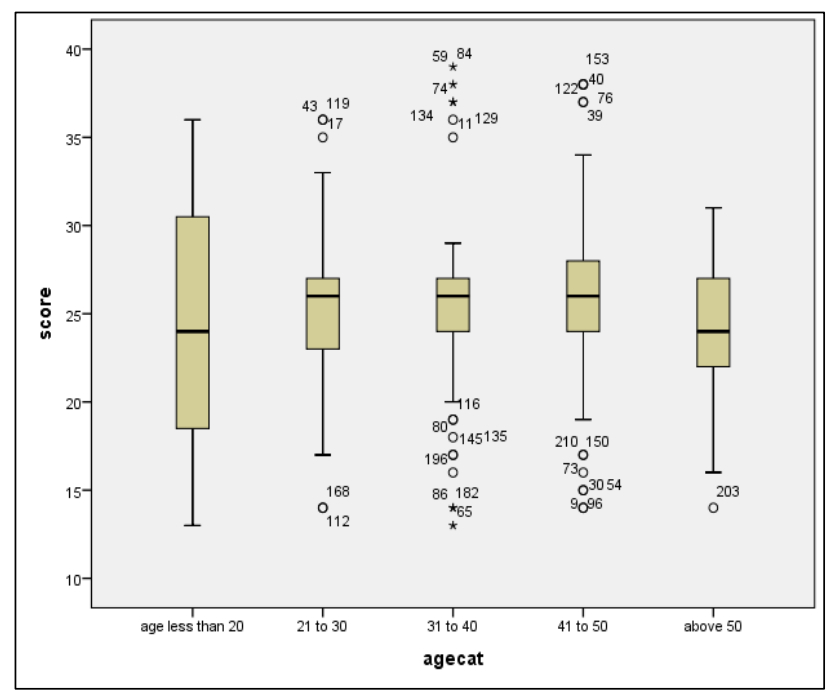

Figure 2: Score of knowledge module in different age groups.

Proper practice includes how and when to take medicine, its relationship with food intake and an account of adverse effects and what to do when faced. They should be taught about dealing with expected situations like missing doses, seeing another doctor, dental procedures etc. There was improper practice regarding intake of multivitamin and alternative medicines. There can be drug interactions when patients who are taking warfarin takes other mediations. When we gave a possible scenario of herbal medications which can improve their health, only $26 \%$ in group A and $44 \%$ of group B avoided it. Many herb medicines will have adverse outcome with warfarin and thus more investment should be done in educating this aspect of the treatment. ${ }^{9,10}$ Information about avoiding physical activity involving mechanical stress was also lacking in patients. Warfarin patients are prone for bleeding and should avoid games like football. The total score was more in patients who were well educated compared with other groups 
$(\mathrm{p}=0.001)$. Figure 1 shows the association of median score and education status. The median score as high among age groups of 41 to 50, but with no statistical difference among groups. Figure 2 shows the change in median score according to age groups. This shows the need of training doctors to talk according to the level of education of the patient. The understanding capacity of the patients will be different and thus the way of explanation also needs to be different. As of now doctor community are not being trained regarding proper communication. This study also shows the importance of including special training for doctors in terms of proper communication to patients.

\section{CONCLUSION}

The study analysed the baseline knowledge, attitude and practice of patients taking warfarin following valve replacement. There exists significant gap in the knowledge about warfarin regarding the effect of food, alcohol, other drugs, time for complete removal of drug form the body. Patients had good attitude towards the surgery and drug use. There were many incorrect practices which the followed and they would follow when given situations of practical importance and thus underlines the need of more clear explanations foreseeing such situations.

Funding: JIPMER intramural grants Conflict of interest: None declared

Ethical approval: The study was approved by the Institutional Ethics Committee of JIPEMR, Puducherry, India

\section{REFERENCES}

1. Wadelius M, Sörlin K, Wallerman O, Karlsson J, Yue QY, Magnusson PK, et al. Warfarin sensitivity related to CYP2C9, CYP3A5, ABCB1 (MDR1) and other factors. The pharmacogenomics J. 2004 Feb;4(1):40.

2. Hernandez W, Gamazon ER, Aquino-Michaels K, Smithberger E, O'brien TJ, Harralson AF, et al. Integrated analysis of genetic variation and gene expression reveals novel variant for increased warfarin dose requirement in African Americans. J Thrombosis Haemostasis. 2017;15(4):735-43.

3. Longtin Y, Sax H, Leape LL, Sheridan SE, Donaldson L, Pittet D. Patient participation: current knowledge and applicability to patient safety. InMayo Clinic Proceedings. 2010;85(1):53-62. Elsevier.

4. Briggs AL, Jackson TR, Bruce S, Shapiro NL. The development and performance validation of a tool to assess patient anticoagulation knowledge. Research in social and administrative Pharmacy. 2005;1(1):40-59.

5. Yahaya AH, Hassali MA, Awaisu A, Shafie AA. Factors associated with warfarin therapy knowledge and anticoagulation control among patients attending a warfarin clinic in Malaysia. J Clin Diagn Res. 2009 Aug;3(4):1663-70.

6. Shrestha S, Sapkota B, Kumpakha A, Acharya U, Sharma R. Evaluation of patients' knowledge on warfarin in outpatient pharmacy of a tertiary care cardiac center. BMC research notes. 2015;8(1):429.

7. Levit LA, Balogh E, Nass SJ, Ganz P, editors. Delivering high-quality cancer care: charting a new course for a system in crisis. Washington, DC: National Academies Press; 2013.

8. Swenson SL, Buell S, Zettler P, White M, Ruston DC, Lo B. Patient-centered communication: do patients really prefer it?. J Gen Intern Med. 2004;19(11):106979.

9. Ge B, Zhang Z, Zuo Z. Updates on the Clinical Evidenced Herb-Warfarin Interactions. Evid Based Complement Alternat Med. 2014;2014:957362.

10. Stenton SB, Bungard TJ, Ackman ML. Interactions between warfarin and herbal products, minerals, and vitamins: A pharmacist's guide. Canadian J Hospital Pharmacy. 2001;54(3).

Cite this article as: Gopisankar MG, Surendiran A, Hemachandren M. An assessment of knowledge, attitude and practices (KAP) towards warfarin medication among patients with prosthetic valve in a tertiary care hospital of South India. Int J Basic Clin Pharmacol 2018;7:1877-81. 